\title{
Caracterización del agente causante de la deformación de los frutos de la uva (Vitis vinifera L.) var. Red Globe en La Unión, Valle del Cauca, Colombia
}

\author{
고 Silvia Patricia López-Zapata, ${ }^{1, *}$, Jairo Castaño-Zapata ${ }^{1}$, \\ (1) Rafael Arango-Isaza ${ }^{2}$, $\odot$ Dayana Andrea Vásquez-Barajas ${ }^{2}$ \\ ${ }^{1}$ Programa de Maestría en Fitopatología, Facultad de Ciencias Agropecuarias, Universidad de Caldas, Manizales, Colombia \\ ${ }^{2}$ Universidad Nacional de Medellín, Escuela de Biociencias, Medellín (Antioquia), Colombia.
}

\begin{abstract}
Resumen
En años recientes una enfermedad caracterizada por la necrosis y el hundimiento de la epidermis de las bayas de la vid (Vitis viinifera L.) se ha venido presentando en la variedad Red Globe, cultivada en predios vitícolas del municipio de La Unión, Valle del Cauca, lo que ha resultado en pérdidas de rendimiento y calidad. Para determinar la etiología de la enfermedad, se recolectaron y procesaron frutos que mostraban los signos típicos de decoloración y posterior necrosis. Con mayor prevalencia se encontró un hongo, que fue sometido a pruebas de patogenicidad y caracterización morfológica mediante microscopía de luz y electrónica (Environmental scanning electron microscopy, ESEM), complementadas con pruebas moleculares. Los postulados de Koch se cumplieron mediante la inoculación de una suspensión conidial de $1 \times 10^{6}$ conidios por $\mathrm{mL}^{-1}$ de agua en bayas sanas de la misma variedad. Al cabo una semana se empezaron a observar signos similares a los observados en campo. Las búsquedas de similitud con la herramienta BLAST mostraron una identidad del $100 \%$ entre las secuencias del espaciador transcribible interno (internal transcribed spacer, ITS) y Colletotrichum aenigma y C. siamense, pertenecientes al complejo de especies Colletotrichum gloeosporioides, lo que proporciona información útil para entender la enfermedad de las bayas de la vid y poder diseñar estrategias de manejo. (C) 2019. Acad. Colomb. Cienc. Ex. Fis. Nat.
\end{abstract}

Palabras clave: Antracnosis; Colletotrichum aenigma; C. siamense; Vid; Vitaceace.

Characterization of the causal agent of the deformation of the fruits of the grape (Vitis vinifera L.) var. Red Globe, in La Unión, Valle del Cauca, Colombia

\begin{abstract}
In recent years, a disease characterized by the necrosis of the grape berries (Vitis viinifera L.) has appeared on the Red Globe variety cultivated in vineyards in the municipality of La Unión, Valle del Cauca, Colombia, resulting in loss of yield and quality. To identify the etiology of the disease, fruits showing the typical symptoms of discoloration and subsequent necrosis were collected and processed. With high frecuency was found a fungus that was subjected to pathogenicity tests and morphological characterization by light and electron microscopy (ESEM). Koch's postulates were fulfilled by the inoculation of a conidial suspension of $1 \times 10^{6}$ conidia per milliliter of water on healthy berries of the same variety. After a week, symptoms similar to those observed in the field began to be observed. The search for similitudes with BLAST showed that the sequences of ITS had a 100\% identity with Colletotrichum aenigma and $C$. siamense belonging to the complex of species of Colletotrichum gloeosporioides, which provides useful information to understand the disease of the grape berries and to design management strategies to control it. C 2019. Acad. Colomb. Cienc. Ex. Fis. Nat.
\end{abstract}

Key words: Anthracnose; Colletotrichum aenigma; C. siamense; Grape; Vitaceae.

\section{Introducción}

La vid es uno de los cultivos de frutales más importantes en el mundo, tanto para el consumo en fresco como para la producción de vino (Sung, et al., 2008). Las regiones productoras están localizadas en los hemisferios norte y sur, en donde se obtiene una cosecha anual (Hernández, et al., 2011). Se estima que la superficie cultivada de vid en el mundo es de 7,6 millones de hectáreas (ha) (Faz, et al.,
2013). En Colombia se cultiva en las zonas del Valle del Cauca y Boyacá; la producción nacional para el año 2016 fue de 30.000 ton en 2.500 ha, con un rendimiento promedio de 10,5 t por ha ${ }^{-1}$ (Agronet, 2018).

\footnotetext{
*Correspondencia:

Silvia Patricia López-Zapata; silvia.821517448@ucaldas.edu.co

Recibido: 4 de marzo de 2019

Aceptado: 11 de mayo de 2019

Editor: Juan Díaz Merlano
} 
Desde el 2016 se ha observado una nueva enfermedad caracterizada por la necrosis de las bayas de la uva (Vitis vinifera L.), en una plantación vitícola del municipio de La Unión, Valle del Cauca, específicamente en la variedad Red Globe. La enfermedad ocurre en focos a partir de los 40 días del inicio de la fructificación y la gravedad aumenta con la edad de los frutos; las plantas con racimos cuyas bayas están afectadas, no presentan alteraciones visibles en los tallos, las hojas, los zarcillos o en otras estructuras que puedan utilizarse como indicadores tempranos de la enfermedad.

Se han reportado síntomas similares a los observados en campo en diferentes variedades de vid (Kummuang, et al., 1996; Peng, et al., 2013; Yan, et al., 2014; Zhang, et al., 2015); el agente causante de la enfermedad se ha clasificado mediante caracteres morfológicos y moleculares entre las especies pertenecientes al género Colletotrichum (Chowdappa, et al., 2009; Sawant, et al., 2012; Peng, et al., 2013).

En el mundo se han reportado pérdidas importantes en diferentes cultivos ocasionadas por especies de Colletotrichum, por ejemplo, en vides muscadinas la disminución varía entre 10 y 50 \% (Kummuang, et al., 1996), en tomate de árbol [Solanum betacea (Cav.) Sendt] puede ser mayor del $50 \%$ (Afanador-Kafuri, et al., 2013), en pimientos la pérdida puede llegar al $100 \%$ (Lewis, et al., 2004) y en pera (Pyrus bretschneideri Rehd.), entre 60 y $90 \%$ (Jiang, et al., 2014); dichas pérdidas representan más de 30 millones de kilogramos de fruta valorados en 30 millones de dólares anuales (Zhang, et al., 2015).

En Colombia no existen reportes de las pérdidas que causa esta enfermedad en la variedad de vid Red Globe, y su impacto en la zona de estudio radica en que es una variedad de mesa que se consume en fresco y, por consiguiente, cada racimo pierde peso a medida que deben retirarse las uvas afectadas, reduciendo así los ingresos económicos de los agricultores.

La caracterización morfológica y genética del agente causante de esta enfermedad proporcionará la información necesaria para establecer las medidas correctas de manejo, evitando el incremento en las pérdidas y su dispersión hacia otras plantaciones y variedades aún no afectadas.

\section{Materiales y métodos}

Descripción de los síntomas de la enfermedad en campo y recolección de muestras. Inicialmente, los síntomas se manifiestan a través de una decoloración rojiza muy tenue (Figura 1A) que avanza gradualmente (Figura 1B, C) y se acompaña del hundimiento progresivo de la epidermis (Figura 1D) seguido de la deformación y la necrosis de los frutos (Figura 1E), los cuales adquieren forma de pasa (Figura 1F). El material afectado se recogió en el predio La Pista, del municipio de La Unión, Valle del Cauca, en un viñedo de 8 años en estado fisiológico 79 (Lorenz, et al., 1994), sembrado con uva de mesa variedad Red Globe, del cual se tomaron bayas que presentaban los signos típicos de la enfermedad. Las bayas se cortaron con tijeras previamente desinfestadas y se almacenaron en bolsas de plástico transparentes para, posteriormente, ser llevadas al Laboratorio de Fitopatología del Departamento de Producción Agropecuaria de la Facultad de Ciencias Agropecuarias de la Universidad de Caldas.

Aislamiento del agente causante de la enfermedad. Se siguió la metodología descrita por Agrios (2005): se cortaron secciones pequeñas de aproximadamente $5 \mathrm{~mm}^{2}$ que incluían tejido afectado y aparentemente sano; luego se colocaron en el interior de una caja de Petri con hipoclorito de sodio al $1 \%$ durante dos minutos y posteriormente se transfirieron a alcohol al $70 \%$ y agua destilada estéril durante 50 segundos; después se pusieron sobre papel toalla estéril para remover el exceso de humedad y a continuación se colocaron cuatro trozos en cada caja de Petri con medio de cultivo de papa, dextrosa y agar (PDA, Merck $\left.{ }^{\circledR}\right)(39 \mathrm{~g}$ por $\mathrm{L}^{-1}$ de agua); las cajas se mantuvieron en incubación a $28{ }^{\circ} \mathrm{C}$ hasta observar algún crecimiento. Una vez se constató el desarrollo del micelio sobre y alrededor de los trozos de tejido previamente sembrados, se procedió a tomar un segmento del sitio de crecimiento activo y se transfirió a nuevas cajas de Petri con PDA, las cuales se sometieron al mismo proceso de incubación hasta obtener colonias puras,

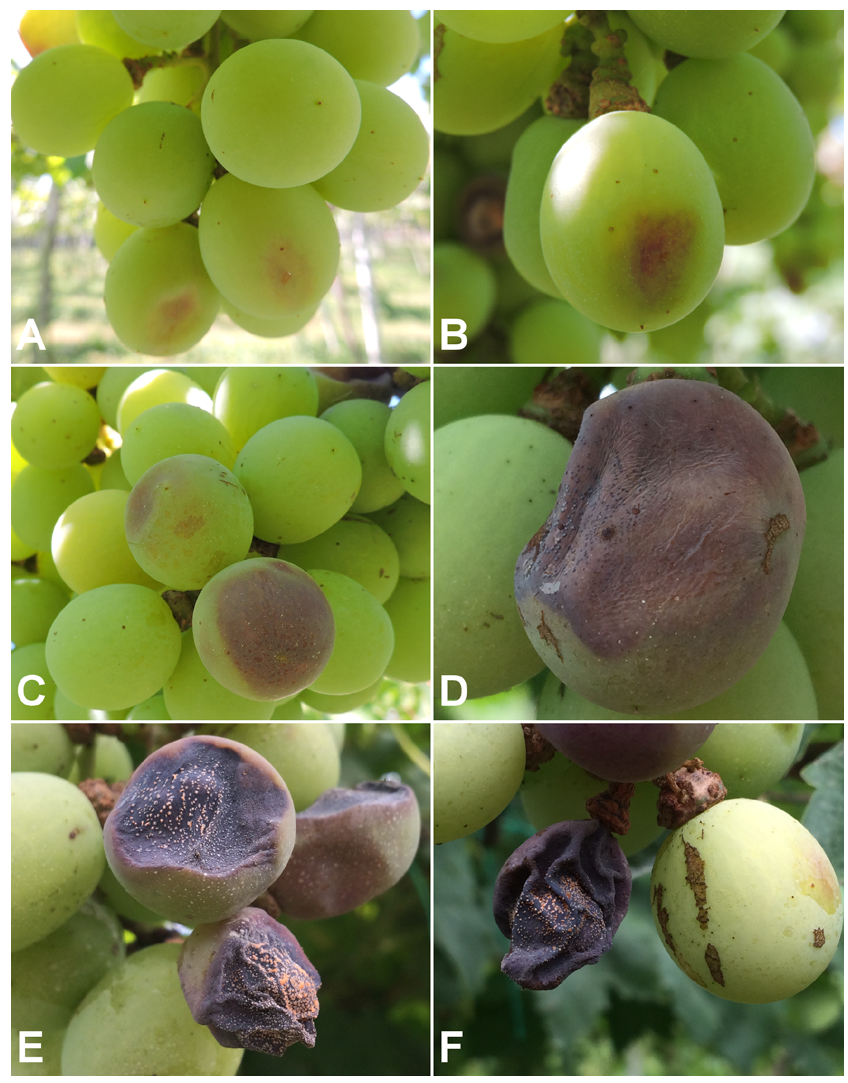

Figura 1. Evolución de los síntomas de la enfermedad en campo. A. Síntomas iniciales de coloración rojiza. B, C. Avance gradual de la coloración. D. Hundimiento de la epidermis. E. Deformación de los frutos acompañada de necrosis. F. Estado final del fruto en forma de pasa. 
uniformes y con esporulación suficiente para realizar las pruebas de patogenicidad y las caracterizaciones morfológicas y moleculares.

La morfología de la colonia y las características de los conidios se registraron después de 15 días de crecimiento a $28 \pm 1^{\circ} \mathrm{C}$ teniendo en cuenta las características de margen de la colonia, la apariencia, el color de la superficie y el reverso, el patrón de esporulación, el color de la masa conidial y la forma y el tamaño de los conidios. La forma de los conidios se observó bajo un microscopio de luz (Leica DM500) y mediante microscopía electrónica de barrido ambiental (ESEM). Con este último método se analizaron también segmentos de tejido de las bayas afectadas y las estructuras reproductivas producidas sobre el medio de cultivo, y las imágenes obtenidas se procesaron usando el programa ImageJ (Ferreira \& Rasband, 2012), con el cual también se midió el ancho y el largo de 50 conidios para determinar su tamaño promedio en micras ( $\mu \mathrm{m})$ (Yan, et al., 2014).

Pruebas de patogenicidad según los postulados de Koch. La suspensión conidial se preparó usando la metodología descrita por Onesti (2014): se inundaron las cajas de Petri con agua destilada estéril, se desechó la superficie del agar, se pasó la solución resultante a través de una gasa doble y con un hemacitómetro se ajustó una concentración de $1 \times 10^{6}$ conidios por $\mathrm{mL}^{-1}$ de agua.

La preparación de los frutos para inocular se efectuó siguiendo la metodología descrita por Riascos (2011), con algunas variaciones, en tres racimos sanos de uva de 330 g correspondientes al estado fisiológico 79 (Lorenz, et al., 1994), que presentaban un tamaño uniforme. Los racimos se lavaron con agua corriente y luego se desinfectaron con hipoclorito de sodio al $1 \%$ durante 5 minutos y posteriormente se lavaron tres veces con agua destilada estéril y se secaron con papel toalla estéril (Ruvishika, et al., 2015); después, los racimos se introdujeron en cajas de plástico con cierre hermético que contenían rejillas; en el fondo de cada caja había una servilleta de papel absorbente humedecido con agua destilada estéril para asegurar condiciones de humedad relativa de alrededor del $95 \%$.

La inoculación se hizo según el método de Cai, et al. (2009): sobre la zona ecuatorial de 35 bayas por racimo se hicieron tres heridas con una aguja estéril y sobre ellas se depositó una gota $(6 \mu \mathrm{L})$ de la suspensión conidial $\left(1 \times 10^{6}\right.$ conidios por $\mathrm{mL}^{-1}$ ); para el tratamiento sin herida se obvió la punción con la aguja estéril y para el testigo la gota de agua destilada estéril se colocó sobre la misma zona empleada en los frutos inoculados.

Los frutos inoculados se mantuvieron en un cuarto de termoterapia a $28{ }^{\circ} \mathrm{C}$ y bajo observación periódica hasta visualizar los síntomas de la enfermedad y de la presencia del patógeno; el hongo se aisló de las bayas infectadas artificialmente usando la técnica descrita y los cultivos resultantes se examinaron con base en la morfología de la colonia y las esporas para confirmar el cumplimiento de los postulados de Koch. La observación del agente causante de la enfermedad mediante microscopía de luz, se complementó con microscopía electrónica de barrido ambiental y, finalmente, el aislamiento se caracterizó molecularmente para determinar la especie del patógeno.

Aislamiento y purificación del ADN fúngico. Los aislamientos se cultivaron en matraces de $100 \mathrm{~mL}$ con $40 \mathrm{~mL}$ de medio Sabouraud durante 12 días a $26{ }^{\circ} \mathrm{C}$. Después de este periodo, se recogió la biomasa y se almacenó a $-70{ }^{\circ} \mathrm{C}$. El ADN se extrajo utilizando el método basado en bromuro de cetiltrimetilamonio (CTAB) (Weising, et al., 1991; Reader \& Broda, 1985), con modificaciones menores (Saldarriaga, 2006), así: los micelios recolectados se maceraron con nitrógeno líquido hasta obtener una textura fina que fue sometida a una nueva suspensión en tubos Eppendorf de 1,5 mL con $700 \mu \mathrm{L}$ del tampón CTAB [100 mM Tris- $\mathrm{HCl}(\mathrm{pH} \mathrm{8,0)}$, $\mathrm{NaCl} 1.4 \mathrm{M}, 20 \mathrm{mM}$ de ácido etilendiaminotetraacético (EDTA) y CTAB al $2 \%$ ] más $4 \mu \mathrm{l}$ de $\beta$-mercaptoetanol, los cuales se incubaron a $65{ }^{\circ} \mathrm{C}$ durante 60 minutos para luego ser sometidos a dos lavados de cloroformo y uno de cloroformo-alcohol isoamílico $(24: 1 \mathrm{v} / \mathrm{v})$. Se recogió la fase acuosa y se precipitaron los ácidos nucleicos con un volumen de isopropanol. El sedimento se recogió por centrifugación a $14.000 \mathrm{~g}$ durante 20 minutos, luego se lavó con etanol al $75 \%$ y se secó a temperatura ambiente. El ADN obtenido fue tratado con ARNasa durante 1 hora a 37 ${ }^{\circ} \mathrm{C}$. Para determinar la calidad del ADN, este se analizó por electroforesis en geles de agarosa al $1 \%$. La concentración se estimó utilizando un espectrofotómetro ND-2000 UVVis (NanoDrop ${ }^{\mathrm{TM}}$ Technologies, USA). Para la reacción en cadena de la polimerasa (PCR), el ADN se ajustó con tris EDTA (TE) a una concentración de $100 \mathrm{ng} / \mu \mathrm{L}$ en tampón TE (10 mM Tris - HCl, 1 mM EDTA; pH 8,0).

Amplificación por PCR. Para la identificación molecular se realizó la amplificación por PCR de la región del ITS. Se utilizaron los cebadores ITS1 (5' TCCGTAGGTGAACC TGCGG 3') e ITS4 (5' TCCTCCGCTTATTGATATGC 3') (White, et al., 1990). La PCR se realizó en un volumen total de $25 \mu \mathrm{L}$, con $100 \mathrm{ng}$ de ADN genómico, 1x de tampón de PCR (Thermo Scientific ${ }^{\mathrm{TM}}$ ), 1,5 $\mathrm{nM}$ de $\mathrm{MgCl} 2,0,2 \mathrm{mM}$ de dNTP, $2 \mu \mathrm{M}$ de cada cebador y 1,5 U de Taq polimerasa (Thermo Scientific ${ }^{\mathrm{TM}}$ ). Las reacciones se incubaron en un termociclador Thermal iCycler ${ }^{\circledR}$ (Bio-Rad Laboratories, Inc., CA, USA) con una temperatura inicial de $94{ }^{\circ} \mathrm{C}$ durante 1 minuto, seguido de 30 ciclos así: $94^{\circ} \mathrm{C}$ durante $1 \mathrm{~min}, 50{ }^{\circ} \mathrm{C}$ durante $1 \mathrm{~min}$ y $72{ }^{\circ} \mathrm{C}$ durante $1 \mathrm{~min}$. Por último, se hizo una extensión final de 5 minutos. Los productos amplificados fueron separados por electroforesis en gel de agarosa al $1 \%$ utilizando GelRed (Biotium, California, USA) como colorante $\mathrm{y}$ visualizados con UV en un transiluminador Biometra (BioDocAnalyze de Analytik Jena AG, Jena, Alemania).

Secuenciación de la región ITS del ADNr. Los productos de PCR se purificaron con el Kit GE Healthcare iLLustra $^{\mathrm{TM}}$ GFX $^{\mathrm{TM}}$ (GE Healthcare, Chicago, USA) siguiendo las instrucciones del fabricante y se secuenciaron con el método de la terminación de la cadena (SANGER REF), servicio prestado por Macrogen Incorporated (Seúl, Corea). 
Análisis de las secuencias. Las secuencias obtenidas se curaron utilizando el programa CLC Main Workbench 7.8 (QIAGEN Bioinformatics, Aarhus, Dinamarca) y se compararon con las bases de datos curadas del GenBank mediante el programa BLASTn.

Análisis filogenético. Con el fin de tener una idea más clara de la identidad del aislamiento se hizo un análisis filogenético utilizando el programa MEGA V 6.0 (Tamura, et al., 2013) con el método de neighbor-joining (Saitou, \& Nei, 1987) y bootstrap de 10.000 réplicas. La distancia evolutiva se calculó mediante el modelo matemático de dos parámetros de Kimura (Kimura, 1980) y la distribución gamma. En el análisis se incluyeron las siguientes 22 secuencias obtenidas del Genbank pertenecientes al complejo C. gloeosporioides: Colletotrichum asianum (JX010192.1), Colletotrichum cordylinicola (JX010226.1), Colletotrichum fructicola (JX010166.1), Colletotrichum gloeosporioides (JX010155.1), Colletotrichum huri (GQ329687), Colletotrichum kahawae subsp. Kahawae (JX010234.1), Colletotrichum musae (JX010143.1), Colletotrichum nupharicola (JX010189.1), Colletotrichum psidii (JX010219.1), Colletotrichum siamense (JX010250.1), Colletotrichum tropicale (JX010275.1), Colletotrichum theobromicola (JX010291.1), Colletotrichum xanthorrhoeae (JX010261.1), Colletotrichum aenigma (JX010244.1), Colletotrichum aeschynomenes (JX010176.1), Colletotrichum alatae (JX010190.1), Colletotrichum alienum (JX010217.1), Colletotrichum aotearoa (JX010220.1), Colletotrichum clidemiae (JX010274.1), Colletotrichum kahawae subsp. ciggaro (JX010230.1), Colletotrichum salsolae (JX010242.1) y Colletotrichum ti (JX010267.1).

\section{Resultados y discusión}

Pruebas de patogenia. El aislamiento inoculado sobre las bayas heridas produjo lesiones pequeñas de color rojizo después de 7 días (Figura 2A, B); en las bayas sin heridas los signos de la enfermedad se observaron 5 días después; las lesiones aumentaron gradualmente de tamaño tornándose oscuras, necrosadas y hundidas (Figura 2C, D); a los 21 de la inoculación todas las bayas se cubrieron con micelio, acérvulos y masas de esporas y, finalmente, terminaron convertidas en una estructura seca y con apariencia de uva pasa (Figura 2E, F); los frutos tratados con agua destilada estéril no desarrollaron signos de la enfermedad. Al aislar de nuevo el hongo de los frutos inoculados y enfermos, se demostró su patogenicidad y se identificó como Colletotrichum spp., cumpliéndose así con los postulados de Koch. El tiempo transcurrido desde la inoculación hasta la esporulación fue similar al reportado por Daykin \& Milholland (1984b) para Colletotrichum sp. en la variedad de vid Carlos en Carolina del Norte (Estados Unidos), quienes observaron la esporulación de este patógeno entre los 21 y los 28 días de la inoculación.

Se demostró que las heridas en las bayas tienen un efecto determinante sobre el desarrollo de la enfermedad, siendo los signos más evidentes en estos frutos que en las bayas no heridas (Figura 3), lo que concuerda con los resultados de Zhang, et al. (2015) y Prihastuti, et al. (2009) al inocular Colletotrichum gloesosporioides y Colletotrichum spp. en hojas de peral y cerezas de café, respectivamente. Además

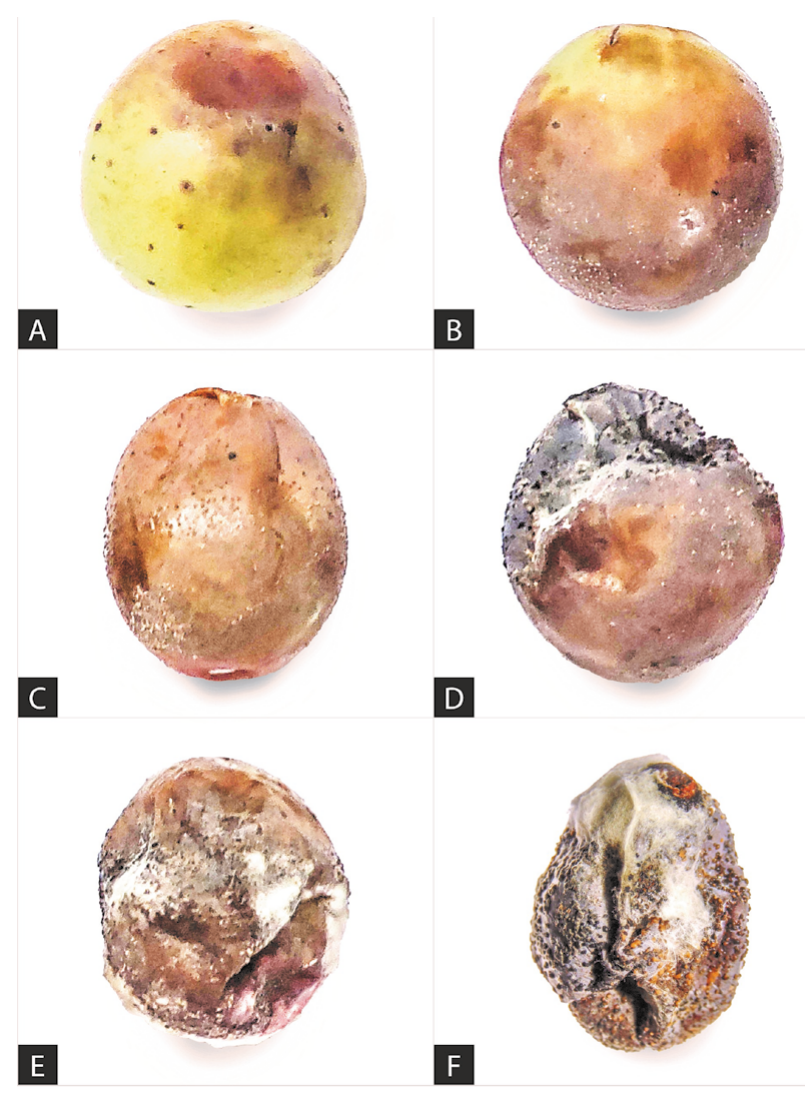

Figura 2. Desarrollo de los síntomas de la enfermedad inducidos mediante inoculación artificial de bayas de uva con conidios de Colletotrichum spp. aislados de frutos enfermos después de una semana (A, B), dos semanas $(\mathbf{C}, \mathbf{D})$ y tres semanas $(\mathbf{E}, \mathbf{F})$.

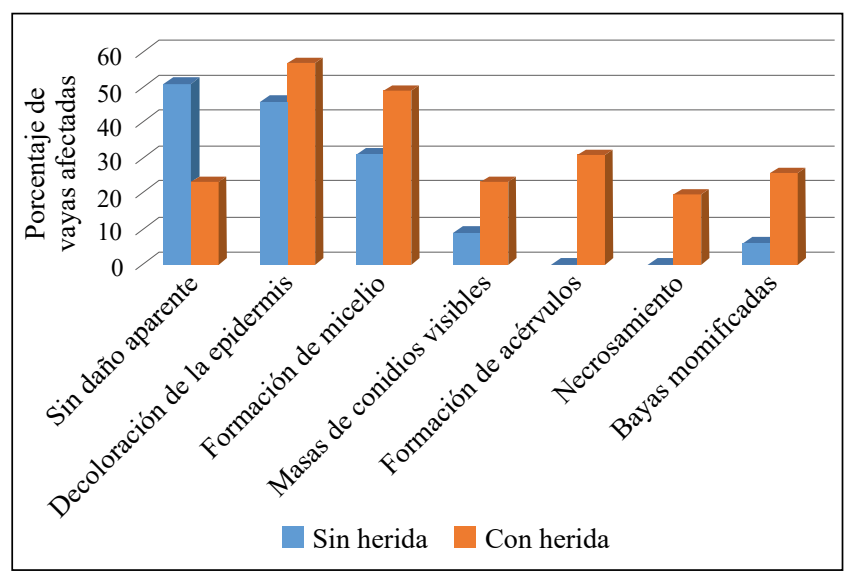

Figura 3. Efecto de las heridas en las bayas sobre el desarrollo de la enfermedad. Obsérvese como las heridas favorecen la expresión de los signos más rápido, así como del hongo y la momificación de los frutos. 
de corroborar el efecto de las heridas en los procesos infectivos de Colletotrichum spp., este resultado explicaría el por qué en campo la incidencia de la enfermedad se observa en mayor porcentaje después del primer raleo, momento en el que se retiran bayas del racimo, lo que, muy probablemente, causa daños imperceptibles en los frutos que posteriormente se constituyen en la vía de entrada para el patógeno; asimismo, la manipulación de los racimos en las plantas puede contribuir a la diseminación del hongo.

Caracterización morfológica. Los cultivos puros obtenidos en PDA presentaron de manera consistente una colonia con márgenes regulares, micelio blanco de aspecto algodonoso con uno o dos anillos concéntricos sutilmente marcados (Figura 4A); en el reverso de la colonia también se observó una apariencia color naranja-salmón, textura densa y anillos concéntricos (Figura 4B). Después de 15 días, las colonias se cubrieron de masas abundantes de conidios color naranja formando estructuras estromáticas redondas y oscuras observables en el fondo de la colonia (Figura 4C, D), cuyo interior siempre se encontró vacío, estructuras que según Weir, et al. (2012) corresponden a un tejido de hifas fuertemente unidas en lugar de células parenquimatosas, lo que las diferencia de peritecios que pueden producirse en el estado perfecto de algunos hongos. Los conidios se encontraron en abundancia sobre los conidióforos cortos (Figura 4E), individualmente fueron unicelulares, lisos,

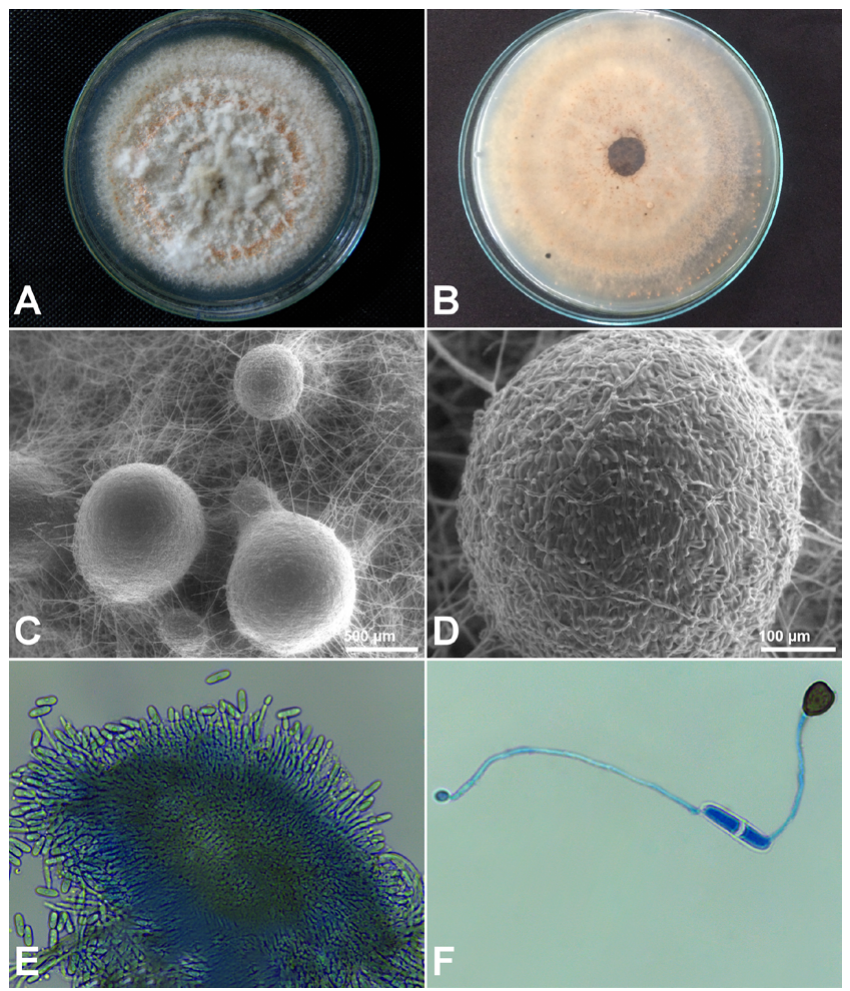

Figura 4. Características del hongo aislado en PDA. A. Apariencia de la colonia en el anverso. B. en el reverso. C, D. Masas de conidios sobre el medio de cultivo. E. Acérvulo, 40X. F. Conidio germinado y apresorio, $100 \mathrm{X}$ hialinos, con ambos extremos redondeados y una longitud que osciló entre los 11,08 y los $14,13 \mu \mathrm{m}$ y un ancho entre 4,04 y $5,70 \mu \mathrm{m}$, características similares a las descritas para Colletotrichum spp. (Freeman, et al., 1998; Greer, et al., 2011; Sawant, et al., 2012; Zhang, et al., 2015). Cuando los conidios germinaron produjeron un tubo germinal hialino, largo a partir de uno de sus extremos, y un apresorio oval con borde liso, no lobulado, de color marrón (Figura 4F). La tasa de crecimiento del hongo fue, en promedio, de 7,5 $\mathrm{mm}$ por día, lo que coincide con el crecimiento reportado para otras especies de Colletotrichum en cítricos (Huang, et al., 2016) y en uva (Whitelaw-Weckert, et al., 2007; Chowdappa, et al., 2009; Yan, et al., 2014).

Análisis del hongo mediante microscopia electrónica de barrido ambiental (ESEM). Al observar el desarrollo del hongo sobre la superficie de los frutos afectados por la enfermedad, se corroboró la identificación del patógeno como Colletotrichum spp. por el desarrollo de las hifas y los acérvulos subepidérmicos, así como de los conidios expulsados en abundancia a través de la ruptura de acérvulos (Figura 5A-D). Además, se pudo observar la formación del apresorio (Figura 5E) y la penetración directa de la hifa responsable de la infección sobre la superficie de una baya (Figura 5F).

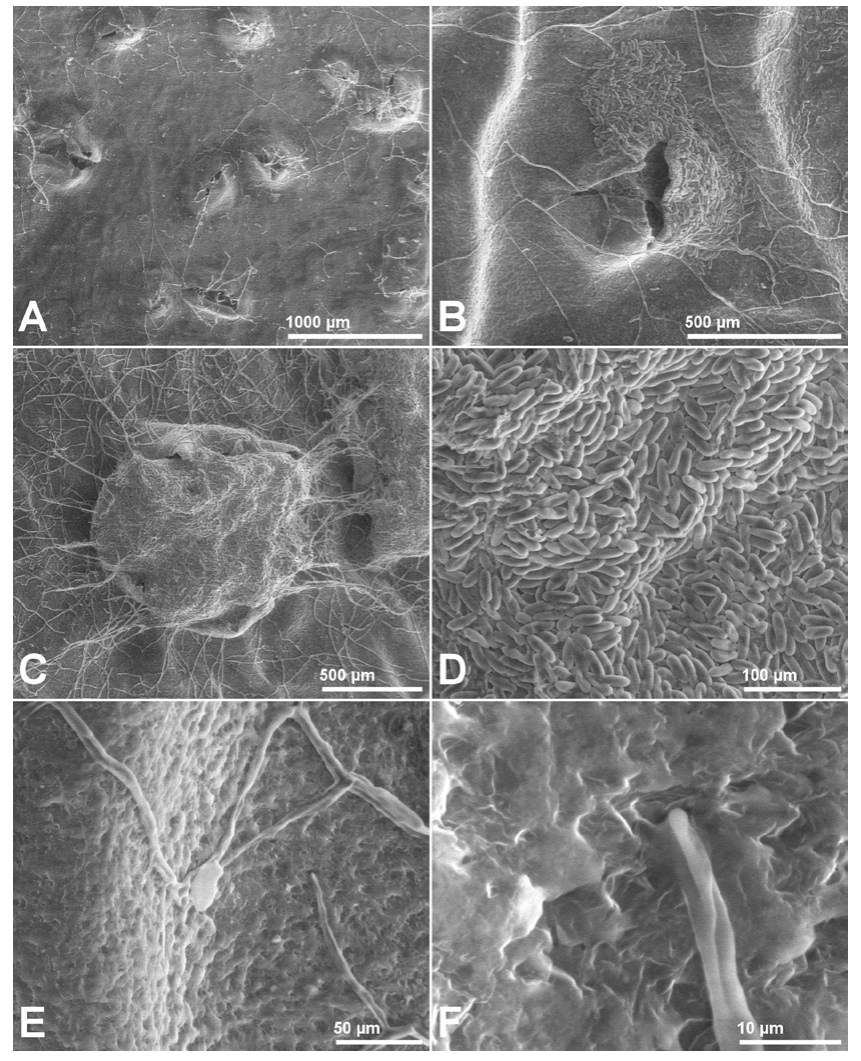

Figura 5. Observación del hongo mediante microscopía de barrido (ESEM) sobre una baya enferma. A. Formación de acérvulos. B, C. Ruptura de un acérvulo y liberación de conidios. D. Morfología de los conidios. E. Formación del apresorio. F. Detalle de una hifa de infección penetrando el tejido de la baya 
Aunque estas observaciones y lo descrito en la literatura (Lewis, et al., 2004; Whitelaw-Weckert, et al., 2007; Peng, et al., 2013) permitieron inferir que se trataba de Colletotrichum spp., con los métodos taxonómicos convencionales no es posible hacer una determinación de especies (Sung, et al., 2008), razón por la cual se procedió a caracterizar el hongo molecularmente.

Caracterización molecular. El análisis del producto amplificado por PCR mostró una banda de aproximadamente $550 \mathrm{pb}$ que corresponde al tamaño esperado para la región amplificada (Figura 6) (Hernández, et al., 2013). Se secuenciaron exitosamente los fragmentos obtenidos de dos réplicas del aislamiento. Las búsquedas de similitud con la herramienta BLAST mostraron que las secuencias del ITS tuvieron un porcentaje de identidad del $100 \%$ con $C$. aenigma y $C$. siamense, pertenecientes al complejo de especies Colletotrichum gloeosporioides (Rhaiem \& Taylor, 2016).

Análisis filogenético. Con el fin de tener una idea más clara de la ubicación taxonómica del hongo, se hizo un análisis filogenético con 22 secuencias obtenidas de GeneBank. El árbol filogenético basado en el método de neighbor-joining y el modelo de los dos parámetros de Kimura evidenció que los dos aislamientos analizados eran más cercanos a las especies de $C$. aenigma y $C$. siamense, formaban un clado monofilético (Weir, et al., 2012) (Figura 7) y coincidían con el análisis de BLAST.

La electroforesis se hizo en gel de agarosa al $1 \%$ y las bandas se visualizaron con GelRed®. El dendograma se generó con el programa MEGA 6.0 utilizando las secuencias ITS1-5.8S-ITS2 obtenidas de GeneBank. Se utilizó el método de neighbor-joining con bootstrap de 10.000 réplicas. La distancia evolutiva se calculó mediante el modelo matemático de dos parámetros de Kimura y la distribución gamma. Las secuencias obtenidas se almacenaron en GeneBank bajo los códigos MK863412 y MK863413 para C. aenigma y C. siamense, respectivamente.

Como se deduce de estos análisis, el agente causante de la enfermedad es una especie perteneciente al complejo de Colletotrichum gloeosporioides, lo que concuerda con los hallazgos de Kummuang, et al. (1996) y Greer, et al. (2011), quienes reportan que las uvas infectadas por Colletotrichum spp. muestran una masa distintiva de esporas de color naranja, los frutos pierden la turgencia y luego se marchitan, y una vez que las bayas están cubiertas con acérvulos, se encogen y se momifican. Además, la secuencia mostró una identidad del $100 \%$ con $C$. aenigma y $C$. siamense (pertenecientes al complejo de especies $C$. gloeosporioides) (Weir, et al., 2012), por lo que no se puede diferenciar de cuál de las dos especies se trata a menos que se haga la secuenciación de otros genes adicionales.

Asimismo, los signos observados en la zona de estudio son similares a los reportados por Yan, et al. (2014) para Colletotrichum spp., quienes indican que las bayas enfermas desarrollan lesiones marrones, circulares, hundidas sobre la

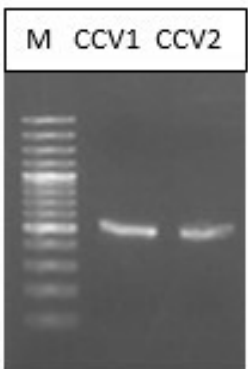

Figura 6. Productos de PCR a partir de ADN total de los aislamientos. De izquierda a derecha se describe la posición de los pozos. M: marcador de peso molecular; $\mathrm{C} 1$ : primera réplica del aislamiento; $\mathrm{C} 2$ : segunda réplica del aislamiento

epidermis, las cuales aumentan de tamaño hasta cubrir completamente la baya y presentan masas de conidios de color rosado-salmón; la diferencia de estas observaciones con respecto a lo hallado en el presente estudio es que los signos aparecieron sobre frutos maduros, en tanto que en este, se observaron en frutos verdes; no obstante, Daykin \& Milholland (1984b) y Freeman et al. (1998) mencionan que las bayas pueden ser susceptibles en cualquier estado de su desarrollo.

En el mismo sentido, las características de color marrón, rojizo o rosa sobre la epidermis, el hundimiento de la superficie de las bayas y las lesiones que se agrandan progresivamente y se cubren de masas de conidios pegajosos de color salmón, están descritas como signos típicos causados por Colletotrichum gloeosporioides y Colletotrichum acutatum J.H. Simmonds ex. J.H. Simmonds (Shiraishi, et al., 2007); además, el secamiento y la momificación de los frutos también se cuentan entre los síntomas descritos por Sung, et al. (2008) para estas dos especies.

El cambio de coloración sobre la epidermis de los frutos está asociado con las respuestas de la planta a las hifas de penetración y varían desde una tinción ligeramente más oscura en el protoplasma hasta la necrosis de las células epidérmicas (Daykin \& Milholland, 1984a; Prakash, et al., 1996), tal como se observó en este caso.

Colletotrichum spp. es un patógeno que tiene un rango muy amplio de hospedantes y es posible encontrar diferentes especies en un solo hospedante o una misma especie en diferentes hospedantes (Freeman, et al., 1998; AfanadorKafuri, et al., 2003); las enfermedades que causa pueden presentarse en la precosecha y en la poscosecha y, además de la producción, afectan el mercado y la posibilidad de exportación (Phoulivong, et al., 2010); asimismo, en las regiones tropicales, subtropicales y templadas se ha observado también la enfermedad denominada antracnosis, la cual produce pérdidas más significativas cuando se presenta en los frutos (Freeman, et al., 1998).

Los efectos de Colletotrichum spp. en estados diferentes a la etapa de maduración también se han reportado en otras especies, en el café (Coffea arabica L.) C. kahawae afecta los frutos en desarrollo (Gil, et al., 2002), y en los perales (Pyrus communis L.) a frutos jóvenes (Jiang, et al., 2014). 


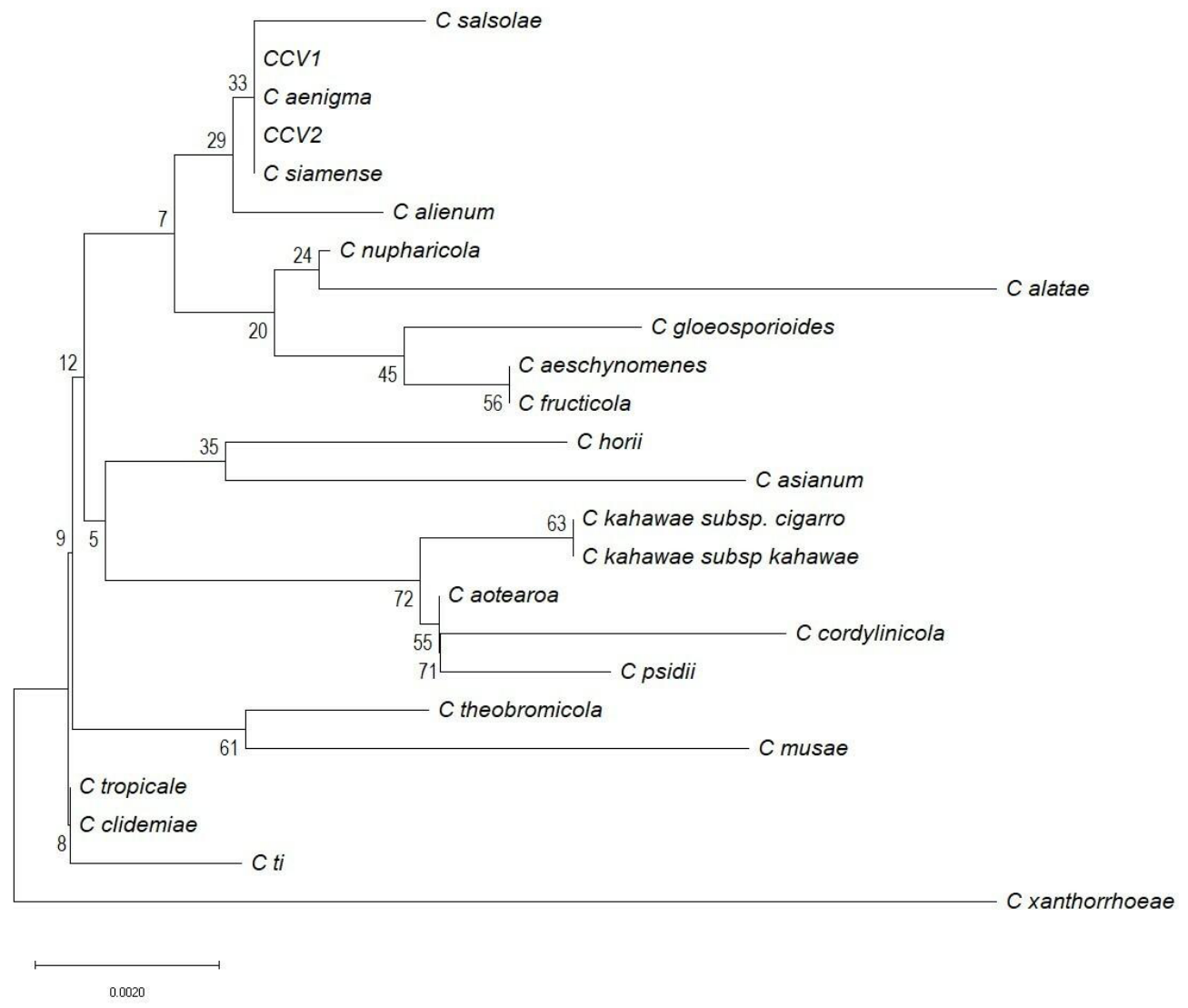

Figura 7. Árbol filogenético que muestra la posición de los dos aislamientos obtenidos de Vitis vinifera con respecto a otros aislamientos de Colletotrichum gloeosporioides obtenidos de GenBank

La antracnosis se ha reportado como una de las enfermedades más importantes del cultivo de la vid debido a las pérdidas económicas que ocasiona (Yan, et al., 2014; Huang, et al., 2016), ya que daña los frutos así como los brotes, las hojas, los zarcillos y las flores (Sawant, et al., 2012).

Durante algún tiempo C. gloeosporioides se consideró el único agente causante de la enfermedad en los racimos de la uva (Whitelaw-Weckert, et al., 2007). Sin embargo, otras especies como C. fructicola, C. viniferum (Peng, et al., 2013), C. aenigma, C. habeiensi (Yan, et al., 2014), C. capsici (Sawant, et al., 2012), C. acutatum (WhitelawWeckert, et al., 2007; Greer, et al., 2011), C. godetiae (Baroncelli, et al., 2014) y C. siamense (Santos, et al., 2018) también se han reportado.

Colletotrichum gloeosporioides se ha encontrado formando un complejo con C. acutatum en diferentes especies de frutos, incluida la uva (Whitelaw-Weckert, et al., 2007). En Australia se encontraron ambas especies en los cultivares Cabernet Sauvignon y Chardonnay (Greer, et al., 2011); también han sido reportadas en China (Suzaki, 2011), Japón (Shiraishi, et al., 2006), Corea (Sung, et al., 2008), y en uvas muscadinas en Mississippi y Carolina del Norte en Estados Unidos (Kummuang, et al., 1996), así como en India (Sawant, et al., 2012).
Los síntomas de la enfermedad causada por Colletotrichum spp. pueden confundirse fácilmente con los de otras enfermedades que también inducen la antracnosis sobre los frutos, como Elsinoe ampeliana, pero difieren en que este último patógeno causa lesiones con centros de color gris $\mathrm{y}$ márgenes de color marrón rojizo a violeta-negro, mientras que Colletotrichum spp. causa lesiones necróticas (Yan, et al., 2014), como se evidenció en este estudio.

Aunque se ha mencionado que la incidencia de la antracnosis es menor en uvas de mesa (Yan, et al., 2014), la presencia de la enfermedad en la zona de estudio únicamente sobre las bayas de la variedad Red Globe quizás es una muestra de la susceptibilidad de esta variedad a $C$. aenigma y $C$. siamense. Algo similar se observó en China, en donde se encontró que $C$. viniferum y $C$. habeiense fueron las especies más virulentas (Yan, et al., 2014).

No se produjeron setas en los acérvulos de los aislamientos, ni tampoco sobre el tejido de las bayas, estructura usada generalmente para diferenciar el género Colletotrichum de Elsinoe ampeliana (Sawant, et al., 2012) y Gloeosporium (Agrios, 2005). Se ha demostrado que la presencia de setas no es una característica estable y depende de otros factores como el sustrato, por consiguiente, no debería considerarse como criterio de identificación (Sawant, et al., 2012). Así 
lo demostraron Greer, et al. (2011) al observar estas estructuras en $C$. gloeosporioides pero no en $C$. acutatum. Por otra parte, Chowdappa, et al. (2009) no observaron setas en aislamientos identificados molecularmente como $C$. gloeosporioides y C. acutatum.

La caracterización molecular del hongo como C. aenigma o C. siamense, pertenecientes al complejo de especies de Colletotrichum gloeosporioides, es extremadamente útil para entender el ciclo de la enfermedad y ayudar a desarrollar estrategias para su manejo adecuado.

\section{Conclusiones}

Mediante pruebas moleculares y de patogenicidad se demostró que el agente causante de la deformación de los frutos de la uva cultivar Red Globe es causada por un complejo de especies de C. gloeosporioides. Mediante microscopía electrónica se confirmó que la presencia de setas en los acérvulos no es una característica que sirva para diferenciar el género Colletotrichum de Gloeosporium. Este es el primer reporte en Colombia de C. gloeosporioides como agente causante de infección en frutos de la vid.

\section{Agradecimientos}

Al Laboratorio de Fitopatología de la Universidad de Caldas y a Vinos Casa Grajales de La Unión, Valle del Cauca.

\section{Contribución de los autores}

Silvia Patricia López Zapata y Jairo Castaño Zapata: identificación de síntomas en campo, aislamiento y purificación, pruebas de patogenicidad y caracterización morfológica del hongo mediante microscopía de luz y electrónica. Rafael Arango Isaza y Dayana Andrea Vásquez: caracterización molecular. Todos los autores participaron en la redacción del documento.

\section{Conflicto de intereses}

Los autores declararan no tener conflictos de intereses.

\section{Referencias}

Afanador-Kafuri, L., Minz, D., Maymon, M., Freeman, S. (2003). Characterization of Colletotrichum isolates from tamarillo, Passiflora, and mango in Colombia and identification of a unique species from the genus. Phytopathology. 93(5):579587. Doi.org/10.1094/PHYTO.2003.93.5.579

Agrios, G.N. (2005). Plant pathology, 5th ed. Academic, New York. 952 p.

Agronet. (2018). Estadísticas de la producción de uva en Colombia. Fecha de consulta: 26 de julio, 2018. Disponible en: http:// www.agronet.gov.co/estadistica/Paginas/default.aspx

Baroncelli, R., Sreenivasaprasad S., Lane, C.R., Thon, M.R., Sukno, S.A. (2014). First report of Colletotrichum acutatum sensu lato (Colletotrichum godetiae) causing anthracnose on grapevine (Vitis vinifera) in the United Kingdom. New Disease Reports. 29: 26. Doi: 10.5197/ j.2044-0588.2014.029.026

Cai, L., Hyde, K.D., Taylor, P.W.J., Weir, B.S., Waller, J., Abang, M.M., Zhang, J.Z., Yang, Y.L., Phoulivong, S., Liu, Z.Y., Prihastuti, H., Shivas, R.G., McKenzie,
E.H.C., Johnston, P.R. (2009). A polyphasic approach for studying Colletotrichum. Fungal Diversity. 39: 183-204.

Chowdappa, P., Reddy, G.S., Kumar, A., Rao, B.M., Rawal, R.D. (2009). Morphological and molecular characterization of Colletotrichum species causing anthracnose of grape in India. The Asian and Australasian Journal of Plant Science and Biotechnology. 3 (1): 71-77.

Daykin, M. E., Milholland, R. D. (1984a). Histopathology of ripe rot caused by Colletotrichum gloeosporioides on muscadine grape. Phytopathology. 74 (11): 1339-1341.

Daykin, M. E., Milholland, R. D. (1984b). Ripe rot of Muscadine grape caused by Colletotrichum gloeosporioides and its control. Phytopathology. 74: 710-714. Doi: 10.1094/ Phyto-74-710

Faz, R., Madero, E., Lagarda, A., Preciado, P., Ávila, C. (2013). Producción y calidad de la uva de mesa de la variedad Red Globe (Vitis vinifera L.) sobre diferentes porta injertos y densidades de población. Agrofaz. 13 (3):105-110. Disponible desde internet en: https://dialnet.unirioja.es/ servlet/articulo?codigo $=5530959$

Ferreira, T., Rasband, W. (2012). ImageJ user guide/IJ 1.46r. Bioimage Informatics. http://rsb.info.nih.gov/ij/docs/guide/ user-guide.pdf

Freeman, S., Katan, T., Shabi, E. (1998). Characterization of Colletotrichum species responsible for Anthracnose diseases of various fruits. Plant Disease. 82 (6): 596-605.

Gil, L.F., Varzea, V.M., Do Ceu Silva, M. (2002). La enfermedad de las cerezas del café -CBD- causada por Colletotrichum kahawae. Avances Técnicos 298. Cenicafé. p. 8.

Greer, L.A., Harper, J.D.I., Savocchia, S., Samuelian, S.K., Steel, S.C. (2011). Ripe rot of South-eastern Australian wine grapes is caused by two species of Colletotrichum: C. acutatum and C. gloeosporioides with differences in infection and fungicide sensitivity. Australian Journal of Grape and Wine Research. 17: 123-128. Doi: 10.1111/j.17550238.2011.00143.x

Harp, T., Pernezny, K., Lewis, M., Miller, S., Kuhn, P., Datnoff, L. (2008). The etiology of recent pepper anthracnose outbreaks in Florida. Crop Protection. 27 (10):1380-1384. Doi: 10.1016/j.cropro.2008.05.006

Hernández, J., Trujillo, Y., Durán, D. (2011). Contenido fenólico e identificación de levaduras de importancia vínica de la uva Isabela (Vitis labrusca), procedente de Villa del Rosario (Norte de Santander). Revista de la Facultad de Química Farmacéutica. 18 (1): 17-25.

Huang, Y.Q., Zang, C.Q., Li, L.X., Liang, C.H., Bai, Y.J., Xie, J.H. (2016). Assessing the genetic diversity of grape ripe rot pathogen Colletotrichum using SRAP markers. Mycosphere. 7 (8): 1103-1110. Doi: 10.5943/mycosphere/si/2c/3

Jiang, J., Zhai, H., Li, H., Wang, Z., Chen, Y., Hong, N., Wang, G., Chofong, G.N., Xu, W. (2014). Identification and characterization of Colletotrichum fructicola causing black spots on young fruits related to bitter rot of pear (Pyrus bretschneideri Rehd.) in China. Crop Protection. 58: 41-48. Doi: 10.1016/j.cropro.2014.01.003.

Kimura, M. (1980). A simple method for estimating evolutionary rates of base substitutions through comparative studies of nucleotide sequences. J. Mol. Evol. 16: 111-120.

Kummuang, N., Diehl, S. V., Smith, B. J., Graves, C.H. Jr. (1996). Muscadine grape berry rot diseases in Mississippi: Disease epidemiology and crop reduction. Plant Disease. 80 (3): 244-247. 
Lewis, M. L., Nava, C., Miller, S. A. (2004). Identification and management of Colletotrichum acutatum on immature bell peppers. Plant Disease. 88 (11):1198-1204. Doi: 10.1094/ PDIS.2004.88.11.1198

Lorenz, D.H., Eichorn, K.W., Bleiholder, H., Klose, R., Meier U., Weber, E. (1994). Phänologische Entwicklungsstadien der Weinrebe (Vitis vinifera L. ssp. vinifera). Codierung und Beschreibung nach der erweiterten BBCH-Skala, Vitic. Enol. Sci. 49: 66-70.

Onesti, G. (2015). Studies on inoculum dynamics of Guignardia bidwellii, causal agent of grape black rot. Tesis doctoral. Università Cattolica del Sacro Cuore, Piacenza. Italia. P. 170.

Peng, L. J., Sun, T., Yang, Y., Cai, L., Hyde, K. D., Bahkali, A. H., Liu, Z. Y. (2013). Colletotrichum species on grape in Guizhou and Yunnan provinces, China, Mycoscience. 54 (1): 29-41. Doi: 10.1016/j.myc.2012.07.006

Peres, N., Timmer, L., Adaskaveg, J., Correl, J. (2005). Lifestyles of Colletotrichum acutatum. Plant Disease. 89 (8): 784-796. Doi: 10.1094/PD-89-0784

Phoulivong, S., Cai, L., Chen, H., Mckenzie, E.H.C., Abdelsalam, K., Chukeatirote, E., Hyde, K. D. (2010). Colletotrichum gloeosporioides is not a common pathogen on tropical fruits. Fungal Diversity. 44 (1): 33-43. Doi: 10.1007/s13225-010-0046-0

Prakash, O., Misra, A.K., Pandey, B.K. (1996). Anthracnose disease of tropical and subtropical fruits. Disease Scenario in Crop Plants. p. 1-27. En: Vol. 1. Fruits and Vegetables. V.P. Agnihotri, O. Prakash, R. Kishun and A.K, Misra. (Editores). International Books and Periodical Supplies Service. Pitampura, Delhi, India.

Prihastuti, H., Mckenzie, E.H.C., Hyde, K.D., Cai, L., Chen, H. (2009). Characterization of Colletotrichum species associated with coffee berries in northern Thailand. Fungal Diversity. 39: 89-109.

Riascos, R. (2011). Caracterización etiológica de la roña de la gulupa (Passiflora edulis Sims.) en la región de Sumapaz, Cundinamarca. Tesis para optar el título de Magister en Ciencias Agrarias con énfasis en Fitopatología. Universidad Nacional de Colombia. Bogotá. Colombia. p. 96.

Reader, U., Broda, P. (1985). Rapid preparation of DNA from filamentous fungi. Letters in Applied Microbiology. 1: 17-20.

Rhaiem, A., Taylor, P. W. (2016). Colletotrichum gloeosporioides associated with anthracnose symptoms on citrus, a new report for Tunisia. European Journal of Plant Pathology. 146 (1): 219-224.

Ruvishika, S. Jayawardena, Wei Zhang, Mei Liu, Sajeewa, S.N., Maharachchikumbura, Ying Zhou, JinBao Huang, Somrudee Nilthong, ZhongYue Wang, XingHong Li, JiYe Yan, Kevin D. Hyde. (2015). Identification and characterization of Pestalotiopsis-like fungi related to grapevine diseases in China. Fungal Biology. 119 (5): 348361. Doi: 10.1016/j.funbio.2014.11.001

Saitou, N., Nei, M. (1987). The neighbor-joining method: A new method for reconstructing phylogenetic trees. Molecular Biology and Evolution. 4 (4): 406-425.

Saldarriaga, A. (2006). Caracterización del agente causante de la antracnosis en tomate de árbol, manzana y mora. Manizales. Tesis de Magíster en Fitopatología. Facultad de Ciencias Agropecuarias. Universidad de Caldas. p. 191.
Santos, R. F., Ciampi-Guillardi, M., Amorim, L., Massola, N. S., Spósito, M. B. (2018). Aetiology of anthracnose on grapevine shoots in Brazil. Plant Pathol. 67: 692-706. Doi: 10.1111/ppa.12756

Sawant, I.S., Narkar, S.P., Shetty, D.S. Upadhyay, A., Sawant, S.D. (2012). Emergence of Colletotrichum gloeosporioides sensu lato as the dominant pathogen of anthracnose disease of grapes in India as evidenced by cultural, morphological and molecular data. Australasian Plant Pathology. 41 (5): 493-504. Doi: 10.1007/s13313-012-0143-5

Shiraishi, M., Yamada, M., Mitani, N., Ueno, T., Nakaune, R., Nakano, M. (2006). Rapid screening assay for Ripe Rot resistance in grape cultivars. Journal of Japanese Society for Horticultural Science. 75 (3): 264-266. Doi: 10.2503/ jjshs.75.264

Shiraishi, M., Koide, M., Itamura, H., Yamada, M., Mitani, M., Ueno, T., Nakaune, R., Nakano, M. (2007). Screening for resistance to ripe rot caused by Colletotrichum acutatum in grape germ plasm. Vitis. 46 (4): 196-200.

Sung, K.H, Wang, G.K, Hae, G.K., Kyung, J.C. (2008). Morphological variations, genetic diversity and pathogenicity of Colletotrichum species causing grape ripe rot in Korea. The Plant Pathology Journal. 24 (3): 269-278. Doi: 10.5423/ PPJ.2008.24.3.269

Suzaki, K. (2011). Improved method to induce sporulation of Colletotrichum gloeosporioides, causal fungus of grape ripe rot. General Plant Pathology. 77 (2): 81-84. Doi: 10.1007/s10327-011-0296-Z

Tamura, K., Stecher, G., Peterson, D., Filipski, A., Kumar, S. (2013). MEGA6: molecular evolutionary genetics analysis version 6.0. Molecular Biology and Evolution. 30 (12): 2725-2729.

Weir, B.S., Johnston, P.R., Damm, U. (2012). The Colletotrichum gloeosporioides species complex. Studies in Mycology. $\mathbf{7 3}$ (1): 115-180. Doi: 10.3114/sim0011

Weising, K., Beyermann, K., Ramser, J., Hahl, G. (1991). Plant DNA fingerprinting with radioactive and digoxigenated oligonucleotide probes complementary to simple repetitive DNA sequences. Electrophoresis. 12: 159-169.

White, T. J., Bruns, T., Lee, S. J. W. T., Taylor, J. W. (1990). Amplification and direct sequencing of fungal ribosomal RNA genes for phylogenetics. PCR Protocols: A Guide to Methods and Applications. 18 (1): 315-322.

Whitelaw-Weckert, M. A., Curtin, S. J., Huang, R., Steel, C. C., Blanchard, C. L., Roffey, P. E. (2007). Phylogenetic relationships and pathogenicity of Colletotrichum acutatum isolates from grape in subtropical Australia. Plant Pathology. 56 (3): 448-463. Doi: 10.1111/j.1365-3059.2007.01569.x

Yan, J.Y., Jayawardena, M.M.R.S., Goonasekara, I.D., Wang, Y. (2014). Diverse species of Colletotrichum associated with grapevine anthracnose in China. Fungal Diversity. 71 (1): 233-246. Doi: 10.1007/s13225-014-0310-9

Zhang, P.F., Zhai, L.F., Zhang, X.K. Huang, X.Z., Hong, N., Xu, W.X., Wang, G.P. (2015). Characterization of Colletotrichum fructicola, a new causal agent of leaf black spot disease of sandy pear (Pyrus pyrifolia). European Journal of Plant Pathology. 143 (4): 651-662. Doi: 10.1007/ s10658-015-0715-7 